\title{
FORÇA, FLEXIBILIDADE E ESPASTICIDADE DOS EXTENSORES DO JOELHO EM PRATICANTES DE MUSCULAÇÃO
}

\author{
STRENGTH, FLEXIBILITY AND SPASTICITY OF KNEE EXTENSORS IN MUSCLE-BUILDING \\ PRACTITIONERS
}

\author{
Amanda Gilvani Cordeiro Matias ${ }^{\mathrm{a}^{*}}$, Ana Lúcia Silva Correia ${ }^{b^{* *}}$, Felix Meira Tavares ${ }^{\mathrm{c}^{* * *}}$ \\ aamanda.ufba@gmail.com, banaluccy27@hotmail.com, cfelixmeira@gmail.com \\ *Universidade Federal da Bahia - Salvador (BA), Brasil \\ **Faculdade Independente do Nordeste - Vitória da Conquista (BA), Brasil \\ ***Universidade Estadual do Sudoeste da Bahia - Vitória da Conquista (BA), Brasil
}

Data de recebimento do artigo: 29/06/2017

Data de aceite do artigo: 03/08/2017

\section{RESUMO}

Introdução: Exercícios de força, flexibilidade e resistência, compilados na prática de musculação, têm a finalidade de manter e melhorar o condicionamento físico e também a estética corporal. Objetivo: Avaliar a relação da força e flexibilidade dos extensores de joelho em mulheres praticantes de musculação. Materiais e métodos: Trata-se de um estudo transversal analítico, realizado em uma academia de ginástica em Vitória da Conquista, na Bahia. Utilizou-se um questionário sociodemográfico com perguntas préestruturadas sobre a temática do estudo. Foi aplicado o teste de força máxima-1-RM com as participantes na cadeira extensora, foi feita a mensuração da flexibilidade de quadríceps femoral através do flexímetro e aplicado o teste de Ely. Resultados: Participaram do estudo 30 mulheres, com idade de 20-35 anos, sendo que $50 \%$ delas era estudante. Foi encontrada correlação positiva, porém não significativa entre força e flexibilidade de quadríceps femoral no grupo avaliado. A avaliaçáo da espasticidade do reto femoral, medido pelo teste de Ely, demonstrou-se positivo em (20) 66,67\% das mulheres, sendo que 70\% delas relataram não realizarem alongamento de quadríceps femoral. Conclusáo: A espasticidade do reto femoral sinaliza possível relação com a ausência de alongamento de quadríceps pré-treino. Entretanto, não houve correlação significativa entre força e flexibilidade dos extensores de joelho nos praticantes de musculação nesta amostra. A prática de musculaçáo não se apresentou significativa com flexibilidade e força de quadríceps femoral isoladamente nas mulheres avaliadas.

Palavras-chave: Musculação; força muscular; flexibilidade; alongamento (DeCS).

\section{ABSTRACT}

Introduction: Exercises of strength, flexibility and resistance, compiled in the practice of muscle-building, have the purpose of maintaining and improving the physical conditioning and also the corporal aesthetics. Objective: To evaluate the relationship of strength and flexibility of knee extensors in women practicing muscle-building. Materials and methods: This is a cross-sectional analytical study carried out at a gym in Vitória da Conquista, Bahia. A sociodemographic questionnaire was used, with pre-structured questions about the study theme. The 1-RM strength test was applied as the participants of the study was in the leg extension, the femoral quadriceps flexibility was measured through the fleximeter and the Ely test was applied. Results: 30 women aged 20-35 years participated in the study, 50\% of which were students. Positive but not significant correlation was found between femoral quadriceps strength and flexibility in the evaluated group. The evaluation of femoral rectus spasticity as measured by the Ely test was positive in (20) $66.67 \%$ of the women, and $70 \%$ of them reported not performing femoral quadriceps stretching. Conclusion: Spasticity of the femoral rectus indicates a possible relation with the absence of pre-training quadriceps stretching. However, there was no significant correlation between strength and flexibility of knee extensors in muscle-building practitioners in this sample. Muscle-building alone did not show significant flexibility and femoral quadriceps strength in the evaluated women.

Keywords: Muscle-building; muscle strength; flexibility; stretching. 


\section{Introdução}

Atualmente, há dupla demanda pela saúde física e pela estética corporal por parte dos indivíduos que praticam exercícios em academias de ginástica. Há também aqueles que visam prevenção e recuperação de lesóes, alívio de tensóes, relaxamento, autoestima, bem-estar, inserindo essa modalidade à rotina para mudar seu estilo de vida e promover a saúde e a qualidade de vida ${ }^{1,2}$.

Qualidade de vida tem sido relacionada com o hábito de realizar os exercícios físicos e as atividades desejadas sem riscos para a integridade do organismo. Nesse sentido, força, flexibilidade e resistência aeróbia são aptidōes básicas necessárias para a saúde do indivíduo e consequentemente para a melhora da qualidade de vida, principalmente porque força muscular e flexibilidade têm sido reportadas como importantes para a independência funcional da vida diária ${ }^{2}$.

A força muscular refere-se à capacidade muscular exercida contra uma resistência e envolve a integridade de fatores fisiológicos e mecânicos que determina a força no movimento em particular ${ }^{3}$. É a habilidade do músculo esquelético de desenvolver força, com objetivo de estabilidade e mobilidade para promover movimento funcional ${ }^{2}$. Seus benefícios consistem na reduçáo da incidência de lesóes no esporte, na melhora do desempenho no esporte e no aumento do tempo de fadiga ${ }^{4,5}$.

A flexibilidade é conceituada como a amplitude máxima fisiológica passiva de movimento articular, dentro dos limites fisiológicos. Refere-se à extensibilidade dos tecidos periarticulares para permitir movimento normal fisiológico de uma articulação. A flexibilidade é a habilidade de mover as articulaçôes do corpo em toda a amplitude do movimento ${ }^{4,5}$. Os mesmos autores consideram-na uma qualidade física proporcionada pela amplitude dos movimentos das diferentes partes do corpo em um sentido, que depende da mobilidade articular e da elasticidade muscular ${ }^{6,7}$. Para Achour, ${ }^{8}$ a manutenção da flexibilidade é importante para melhorar a qualidade do movimento, possibilitando realizar grandes amplitudes de movimento, reduzindo os riscos de lesóes musculares e articulares e potencializando o controle motor e a ação mecânica.

O alongamento é uma técnica utilizada para melhorar a flexibilidade por meio da elasticidade muscular, ao colocar o músculo alongado além de seu tamanho habitual. É uma modalidade de exercício físico que pode manter ou aumentar a capacidade motora de flexibilida$\mathrm{de}^{3,8,9}$. Os exercícios de alongamento são utilizados para promover qualidade de vida, pois aliviam as tensôes e os encurtamentos, melhoram a circulação, melhoram a prática esportiva, além de atuar na redução de lesōes s,10. $^{8,}$.

A manutenção da força e flexibilidade em padróes adequados é essencial para o bom funcionamento musculoesquelético, contribuindo para a preservação de músculos e articulaçôes ao longo da vida, atuando na diminuiçấo de risco de lesóes e melhorando significativamente o movimento e a postura corporal. Essas capacidades físicas decrescem significativamente com a idade, no entanto tal diminuição pode ser minimizada com atividades físicas regulares e níveis de condicionamento ${ }^{1,3,8}$.

A prática regular de exercícios físicos visando a força muscular e flexibilidade exerce papel importante na aptidão física e na saúde e ao longo da vida. A musculação possui prioridades de estimular a saúde geral e a qualidade de vida, sendo o exercício mais eficiente e seguro em todas as faixas etárias, e tende a ser indicada como atividade base, pois proporciona aumento da massa óssea, aumento da massa muscular e reduçáo do tecido adiposo ${ }^{2,7,11}$.

A musculação é a modalidade de exercício mais praticada em academias de ginásticas e desportivas, com objetivos competitivos, de reabilitação, de treinamento esportivo, estético-corporal, de lazer e profilaxia e também relacionados ao bem-estar e à saúde. $\mathrm{O}$ treino de força exerce um papel importante no condicionamento físico em geral, na performance esportiva, na reabilitaçáo de lesóes e no aumento da massa muscular ${ }^{12}$. Inclui o uso de pesos livres, máquinas, peso corporal e outros equipamentos para melhorar força, potência e resistência muscular ${ }^{6,12}$.

O número de pessoas praticantes de exercícios físicos vem crescendo nos últimos anos, sendo que o Brasil está apontado em sétimo lugar em número de praticantes da modalidade aeróbica no mundo, superando a França, o Japão e a Holanda, e em primeiro na América Latina. Esse percentual atinge 2-3\% da população brasileira praticante regular desse exercício físico, correspondendo a cerca de 3,7 milhões de pessoas. Em 2013, esse percentual de pessoas que praticam atividades físicas passou para cerca de 33,8\% de acordo com pesquisas da Vigilância de Fatores de Risco e Proteção para Doenças Crônicas por Inquérito ${ }^{13}$, o que representa um aumento de $11 \%$, sendo que as mulheres tiveram um acréscimo maior desse percentual ${ }^{13}$.

A prática da musculação atrelada ao objetivo de promover modificaçôes dos níveis de flexibilidade e força muscular requer avaliaçóes e acompanhamento sistematizados, como controle gerador de informaçóes para fundamentar decisões clínicas que tragam maior benefício ao praticante de exercícios físicos, contribuindo para manutenção da saúde e qualidade de vida.

\section{Materiais e métodos}

Trata-se de um estudo transversal e analítico, realizado em uma academia de ginástica de abril a junho de 2016, em Vitória da Conquista, Bahia. A população foi 
constituída por 30 mulheres praticantes de musculação, frequentadoras da academia. A amostra foi estabelecida por conveniência a partir dos seguintes critérios de inclusão: pertencerem ao sexo feminino; ter idade de 18-35 anos; ser praticante de musculação há no mínimo três meses e duas vezes por semana; aceitar voluntariamente participar das etapas do estudo. Os Critérios de exclusão foram: ser diagnosticada com doenças osteomioarticular, obesidade no grau II ou III $\left(>34 \mathrm{hg} / \mathrm{m}^{2}\right)$, doenças degenerativas ou de membros inferiores; praticar outra modalidade de exercício físico concomitante para ganhar força e flexibilidade.

Foi utilizada entrevista pré-estruturada, considerando critérios de inclusão e exclusão, associada a um questionário sociodemográfico com perguntas referentes à idade, à profissão, ao tempo de prática da musculação, à pratica de alongamento, ao ciclo menstrual. Foram coletados dados sobre a altura, o peso, o índice de massa corpórea (IMC), a perimetria de coxa. Foram aplicados testes de 1-RM (flexibilidade do quadríceps femoral) e o teste de Ely ${ }^{14}$. A aferição da força e flexibilidade foram coletadas antes do treinamento diário das voluntárias, para evitar vieses de interferência nessas variáveis.

A perimetria da coxa foi realizada com fita métrica, colocada ao redor da perna de modo a ficar justa sem apertar, sendo que a pessoa estava em ortostase em frente ao avaliador, com as pernas ligeiramente afastadas, distribuindo o peso do corpo sobre as duas pernas, executou-se a medida na porção medial posicionando a fita na metade entre a linha inguinal e a borda proximal da patela, conforme protocolo ${ }^{14}$.

O teste de força máxima de 1-RM foi realizado conforme protocolo ${ }^{14}$. Estimou-se um peso inicial próximo e abaixo da capacidade máxima de levantamento de cada participante, sendo o peso acrescentado progressivamente a cada levantamento até a capacidade máxima. $\mathrm{O}$ acréscimo de peso foi de 5 e $10 \mathrm{~kg}$, com intervalo de repouso de um minuto, para a recuperação muscular suficiente para continuar o levantamento de peso. A pessoa avaliada era conduzida à cadeira extensora romana, sendo posicionada no aparelho com as costas bem apoiadas e com o eixo do aparelho próximo dos eixos articulares dos joelhos, com maior amplitude possível. O movimento consistia em realizar a extensão completa do joelho. $\mathrm{O}$ teste era finalizado quando a pessoa náo conseguisse mais levantar o peso.

A flexibilidade do quadríceps femoral foi mensurada pelo flexímetro, conforme protocolo ${ }^{15}$, sendo a pessoa avaliada em decúbito ventral, com os joelhos apoiados na maca e os tornozelos ultrapassando sua borda. O flexímetro foi fixado na face lateral da perna em seu terço médio. $\mathrm{O}$ movimento era realizado passivamente, flexionando o joelho e levando o tornozelo em direção ao glúteo, com observação atenta de compensaçóes de anteversão pélvica. Foram realizadas três medidas para obtenção da média.

$\mathrm{Na}$ mensuração do encurtamento do reto femoral pelo Teste de Ely ${ }^{14}$, verificou-se a presença de retração do reto femoral. $\mathrm{O}$ procedimento exigiu que a avaliada estivesse em decúbito ventral, o examinador realizou a flexão passiva de joelho e utilizou a fleximetria para medir o grau de flexão do quadril, com o posicionamento do flexímetro na face lateral da coxa. $\mathrm{Na}$ presença de retração do reto femoral, mensurou-se o aumento do grau de flexão do quadril, ou seja, o deslocamento anterior da pelve.

Em atendimento aos requisitos da ética na pesquisa, todos os procedimentos foram realizados após aprovação pelo Comitê de Ética e Pesquisa (CEP) da Faculdade Independente do Nordeste (FAINOR), cujo CAAE é 31783814.1.0000.5578. Todas as voluntárias assinaram o Termo de Consentimento Livre e Esclarecido (TCLE), conforme prevê a Resolução 466/12, do Conselho Nacional de Saúde - CNS/CONEP/MS.

Foi utilizada a estatística descritiva, como média, desvio-padrão, frequência, além do teste de correlação de Pearson e Teste T Student. Para tabulaçáo de dados, utilizou-se o programa Microsoft Office Professional Plus 2010, Microsoft Excel versão 10 e o programa GraphPad Prism 2007 versão 5 para a análise de correlação.

\section{Resultados}

Participaram da pesquisa 30 mulheres praticantes de musculação, frequentadoras da academia. Dentre elas, $21(70 \%)$ estavam na faixa etária de 20-25 anos e $15(50 \%)$ eram estudantes universitárias. Quanto ao tempo de musculação, $9(30 \%)$ praticavam entre 3-6 meses sendo que $11(36,66 \%)$ delas frequentavam a academia seis dias por semana. Na Tabela 1, observa-se que o teste de força de 1-RM de quadríceps femoral totalizou $11(36,66 \%)$ participantes que atingiram força de $81-100 \mathrm{~kg}$ na fleximetria em extensão de joelho direito e $13(43,33 \%)$ mulheres que atingiram angulação de 121-130 graus, enquanto do joelho esquerdo, $12(40 \%)$ atingiram a mesma angulação. Referente ao teste de Ely, 20 (66,66\%) praticantes apresentaram o teste positivo. Ao serem questionadas se realizavam alongamento de quadríceps femoral, 21 (70\%) responderam que não, ou que não realizavam corretamente. Nas medidas antropométricas, 11 (36,66\%) das mulheres apresentavam IMC entre $15-20 \mathrm{~kg} / \mathrm{m}^{2}$, conforme demonstrado na Tabela 1. 
Tabela 1: Características das variáveis de força e fleximetria dos extensores do joelho e teste de Ely.

\begin{tabular}{|c|c|c|c|c|c|}
\hline CARACTERÍSTICA & CLASSE & No & $\%$ & $\Sigma$ & $\delta$ \\
\hline \multirow{5}{*}{ TESTE DE 1-RM (kg) } & $40-60$ & 4 & 13,33 & \multirow{5}{*}{87,733} & \multirow{5}{*}{22,445} \\
\hline & $61-80$ & 7 & 23,33 & & \\
\hline & $81-100$ & 11 & 36,66 & & \\
\hline & $101-120$ & 5 & 16,33 & & \\
\hline & $121-140$ & 3 & 10 & & \\
\hline \multirow{5}{*}{ FLEXIMETRIA DO JOELHO DIREITO (GRAUS) } & $90-100$ & 1 & 3,33 & \multirow{5}{*}{118,814} & \multirow{5}{*}{8,592} \\
\hline & $101-110$ & 3 & 10 & & \\
\hline & $111-120$ & 12 & 40 & & \\
\hline & $121-130$ & 13 & 43,33 & & \\
\hline & $131-140$ & 1 & 3,33 & & \\
\hline \multirow{5}{*}{ FLEXIMETRIA DO JOELHO ESQUERDO (GRAUS) } & $90-100$ & 0 & 0 & \multirow{5}{*}{118,997} & \multirow{5}{*}{9,089} \\
\hline & $101-110$ & 7 & 23,33 & & \\
\hline & $111-120$ & 8 & 26,66 & & \\
\hline & $121-130$ & 12 & 40 & & \\
\hline & $131-140$ & 3 & 10 & & \\
\hline \multirow{2}{*}{ TESTE DE ELY } & Positivo & 20 & 66,66 & & \\
\hline & Negativo & 10 & 33,33 & & \\
\hline
\end{tabular}

Fonte: Elaborada pelos autores, 2017.

Legenda: $\mathrm{N}^{\circ}=$ números; $\%=$ porcentagem; $\sum=$ média $\delta=$ desvio padrão.

Quanto à relação entre força e flexibilidade de quadríceps femoral, não houve correlação significativa entre as variáveis de força e flexibilidade $(\mathrm{r}=0,162$; $\mathrm{p}<0,397$ ), demonstrados no Gráfico 1 . Houve correlação significativa entre o tempo de musculação com a força muscular, foi evidenciado que, quanto maior o tempo de musculação, maior a força muscular de quadríceps femoral $(\mathrm{r}=0,41 ; \mathrm{p}<0,024)$, e também foi possível verificar que a correlação entre tempo de musculação com a flexibilidade não foi significante $(r=0,057 ; p<0,763)$. A relação da flexibilidade entre as mulheres que realizavam alongamento e aquelas que não realizavam foi positiva, entretanto não demonstrou diferença significativa entre os grupos $(t=0,498$; $\mathrm{df}=28 ; \mathrm{p}<0,621)$.

Gráfico 1: Gráfico da relação entre força muscular e flexibilidade de quadríceps femoral.

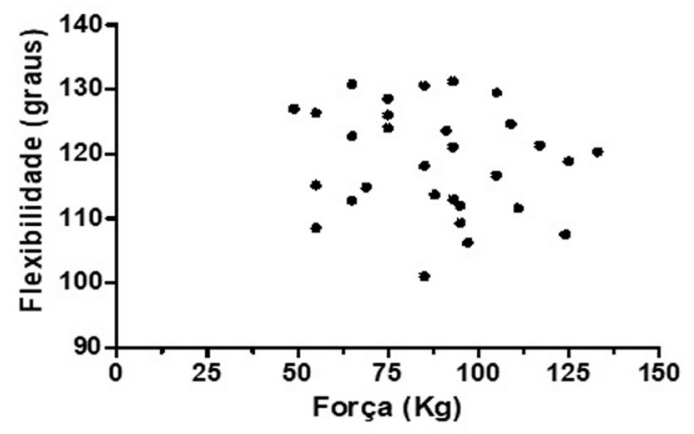

No Gráfico 2, observa-se a relação quanto ao nível de força muscular de quadríceps femoral com as praticantes que realizavam alongamento e as participantes que não realizavam alongamento, também não houve diferença significante entre os grupos $(t=0,448 ; d f=28 ; p<0,657)$. Referente ao índice de massa corporal (IMC), nota-se que não houve correlação significante com a medição da flexibilidade $(\mathrm{r}=0,122 ; \mathrm{p}<0,519)$ e com a perimetria da coxa com a fleximetria $(r=0,016 ; p<0,917)$.

Gráfico 2: Gráfico da diferença entre os grupos que realizavam alongamento e que não realizavam alongamento, quanto à força de quadríceps femoral.

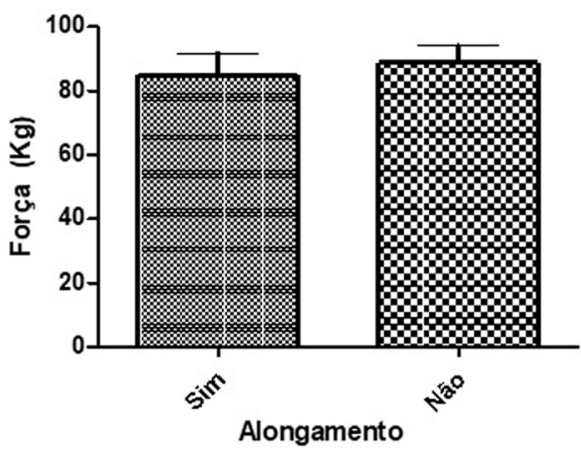

Fonte: Elaborado pelos autores, 2017.

O Gráfico 3 explicita a relação do Teste de Ely com a flexibilidade do quadríceps femoral, demonstrando ausência de significância estatística entre as voluntárias

Fonte: Elaborado pelos autores, 2017. 
com encurtamento de reto femoral positivo e aquelas com encurtamento negativo $(t=0,625 ; \mathrm{df}=28 ; \mathrm{p}<0,536)$. A relação do período fértil das mulheres avaliadas com a flexibilidade de quadríceps femoral não apresentou diferença estatística significante em comparando-se as que estavam no período fértil e as que não estavam $(t=0,036$; $\mathrm{df}=28 ; \mathrm{p}<0,971)$.

Gráfico 3: Gráfico da diferença do Teste de Ely positivo e negativo quanto à flexibilidade de quadríceps femoral.

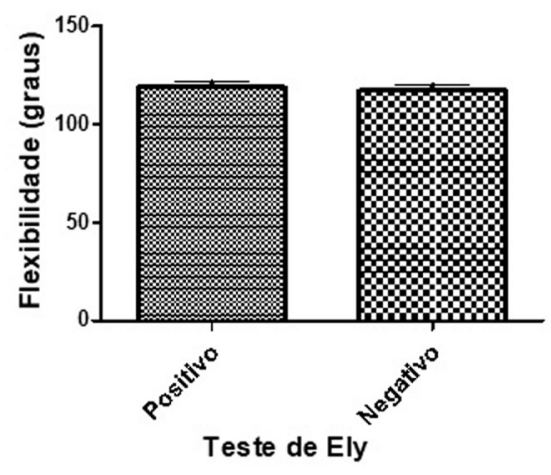

Fonte: Elaborado pelos autores, 2017.

\section{Discussão}

Este estudo teve o objetivo de verificar a relação entre força muscular e flexibilidade da musculatura quadríceps femoral em mulheres praticantes de musculação. Visto que é importante que o exercício planejado contemple esse trabalho de forma integrada para fortalecer a função musculoesquelética e evitar possíveis lesões. O exercício físico é uma importante estratégia de promoção da saúde e prevençáo do adoecimento. Apesar de evidências cientificas justificarem seus benefícios, ainda há lacunas e dificuldades que necessitam ser elucidadas ${ }^{1,2,4}$.

Neste estudo foi observado que não houve correlação significativa entre os níveis de força e a flexibilidade de quadríceps femoral em mulheres praticantes de musculaçáo, esclarecendo que o ganho de força muscular não necessariamente induz à redução dos níveis de flexibilidade. Esse achado corrobora com um estudo prévio $^{15}$, que avaliou 67 pessoas praticantes de esporte do sexo feminino e verificou a impulsão vertical e fleximetria de quadril, joelho e tornozelos. Outro estudo ${ }^{16}$ conduzido com uma amostra de 18 desportistas amadores avaliou a força dos flexores de joelho através de teste de resistência de força com $25 \mathrm{~kg}$ e goniometria digital de quadril. E também outra pesquisa ${ }^{17}$ composta por 20 mulheres e 30 homens universitários demonstrou medidas de flexibilidade pelo Flexitest e pelo Teste 1-RM do legpress e handgrip, chegando a resultados semelhantes.

Outros estudos encontraram resultados diferente dos nossos achados, apresentando uma correlação significativa quando avaliaram em 12 sessóes de treino de força um grupo de voluntários e encontraram $82,35 \%$ da sua amostra com importante ganho de flexibilidade $(1-3 \mathrm{~cm})$, medidos pelo banco de Wells ${ }^{8}$. Em outra pesquisa ${ }^{1}$, foi constatado um aumento significativo na amplitude de movimento de perna entre os indivíduos avaliados que eram praticantes de exercício físico em academia de ginástica um percentual de $60,86 \%$, sendo prevalente em mulheres.

Neste estudo, foi possível verificar que, mesmo sem a adoção de um trabalho específico de alongamento, a prática regular da musculação foi favorável na manutenção dos níveis de flexibilidade das mulheres avaliadas. Mas vale ressaltar a necessidade da realização de outros estudos com um maior número amostral, para esclarecer esta relaçáo sobre o ganho da força, da massa muscular e a possível diminuição ou não da flexibilidade.

Os exercícios com carga para induzir o ganho de hipertrofia muscular também aumentam a elasticidade muscular, pois eles forçam o limite das articulaçóes e conjuntamente beneficiam o tecido conjuntivo que recobre as fibras musculares, aumentando a vascularização local. Esse tecido é viscoso e elástico e, se aplicada determinada força no músculo hipertrofiado, ele irá se alongar mais em relação ao músculo não treinado ${ }^{8}$. Vale destacar que, neste estudo, $70 \%$ das participantes da amostra declararam não realizar alongamento de quadríceps femoral no pré-treino de força muscular. De acordo com o mesmo autor, o alongamento realizado antes do treino prepara o organismo para o exercício e no pós-treino de força favorece a dissipação do lactato residual, ajudando a manter a viscosidade e a elasticidade do tecido conjuntivo. Outro benefício do alongamento executado pré-treino refere-se ao aquecimento corporal, que auxilia na prevenção de lesóes e dores musculares, além de potencializar processos de contração muscular e recuperação dos músculos ${ }^{1,8,18}$.

Estas prerrogativas remetem à importância do acompanhamento de um profissional competente e da avaliação clínica do aspirante a qualquer modalidade desportiva. Deve-se principalmente dispensar atenção sobre a musculatura hipertrofiada antes de desenvolver exercícios de flexibilidade, pois a hipertrofia pode funcionar como resistência ao alongamento. $\mathrm{O}$ ideal seria o desenvolvimento simultâneo do alongamento e da flexibilidade, mas com a adoção de protocolos orientados por profissional competente, conforme a 
capacidade ou limitação do indivíduo ${ }^{18,19,20}$. Para esses autores, os exercícios de resistência e alongamentos devem ser realizados paralelamente para evitar desequilíbrios no desenvolvimento do organismo e alcançar os resultados pretendidos.

Recomenda-se que, antes do trabalho de força muscular, deve-se desenvolver a flexibilidade articular. Se o indivíduo não tiver boa flexibilidade, o treinamento pode gerar condição de stress e dor muscular, além de possíveis casos de lesóes ${ }^{20}$. O desenvolvimento de exercícios devidamente dosados, com equilíbrio, para desenvolver força e flexibilidade é ideal para saúde e manutenção da qualidade de vida de indivíduos atletas ou amadores, destacando a importância do alongamento em protocolos e em programas de exercícios. Os pesquisadores reportam que a flexibilidade se refere à habilidade muscular para alongar-se, permitindo o movimento articular através de sua amplitude de movimento, que tem papel importante no equilíbrio postural $^{2,6,12,20}$.

A variável flexibilidade, neste estudo, não apresentou diferença significativa entre os grupos de mulheres que estavam no período fértil e o das que não estavam. Esses resultados corroboram com o de um estudo ${ }^{20}$ que avaliou 20 mulheres com idade entre 18 e 35 anos que praticavam ginástica em uma academia e testou os movimentos de ombro, quadril, joelho e lombar, constatando que as três fases do ciclo menstrual (folicular, ovulatória e lútea) não influenciaram na flexibilidade. É provável que as oscilaçóes dos fatores hormonais femininos (estrogênio e progesterona) atuam na debilidade dos sistemas articulares, ligamentares, deixando-os mais frouxos, do ponto de vista da fisiologia. Entretanto, esta relação da frouxidão ligamentar em mulheres no período menstrual não foi demonstrada nem com aumento, nem com diminuiçáo da flexibilidade neste estudo. Esses achados corroboram com pesquisadores que avaliaram mulheres praticantes de musculação e influência de fatores hormonais na flexibilidade ${ }^{20}$.

Desse modo, considerando as limitaçóes desta pesquisa referentes ao pequeno número amostral, assim como por náo se tratar de estudo multicêntrico, sugere-se novas pesquisas sobre essa temática. Não apenas as mulheres praticantes de musculação, mas também de outras modalidades de exercícios, considerando as flutuaçóes que envolvem o aspecto fisiológico hormonal das mulheres, podem sofrer influências nos níveis de flexibilidade e de força muscular em relação à prática do alongamento, investigando possíveis respostas musculoesqueléticas frente à musculação.

Portanto, as perspectivas apontam que a adequada aptidão física, flexibilidade e força muscular estão diretamente relacionados com a saúde do sistema musculoesquelético, com a manutenção e a promoção da saúde e com a funcionalidade para atividades da vida diária e instrumentais, além da própria segurança e efetividade das atividades físicas, conforme corroboram pesquisadores dessa tematica ${ }^{2,10,16,18}$.

\section{Conclusão}

Os resultados obtidos neste estudo apontam a ausência de correlaçáo significativa entre a força e flexibilidade na musculatura do quadríceps femoral em mulheres praticantes de musculação, frequentadoras de academias. Assim, a modalidade do treino de força muscular não reduziu os níveis de flexibilidade nesse grupo. Verificou-se também que mesmo a ausência do trabalho específico de alongamento pré-treino demonstrou interferir na redução da flexibilidade de forma importante, embora esteja bem relatado na literatura a importância do alongamento como precursor benéfico do exercício físico.

A literatura é consensual quanto às atividades estimuladas de forma conjunta no treinamento de força e flexibilidade parecerem ser mais efetivas e benéficas na pratica de exercícios, sendo bem indicada a inclusão da modalidade aeróbica, visando qualidade de vida e melhor desempenho das atividades diárias. Vale ressaltar o cuidado preventivo para desempenho de treinamento de força muscular, flexibilidade e equilíbrio a fim de evitar lesóes musculares e articulares no âmbito das academias de ginástica. O Colégio Americano de Medicina do Esporte recomenda que a busca pela flexibilidade deve estar associada à prática de exercícios de alongamentos para manter e aumentar a amplitude de movimento, sendo que esta condição reduz o risco de lesões no sistema musculoesquelético.

\section{Referências}

1. Shiromoto CE, Oliveira Filho A, Bertolini SMMG. Implicaçóes da prática de exercícios resistidos sobre a flexibilidade. Rev Educ Fís. 2002;13(1):55-62.

2. Paulo AC, Ugrinowitsch C, Leite GS, Arsa G, Marchetti $\mathrm{PH}$, Tricoli V. Efeito agudo dos exercícios de flexibilidade no desempenho de força máxima e resistência de força de membros inferiores e superiores. Motriz Rev Educ Fís. 2012;18(2):345-55.

3. Oliveira LV, Saad MC, Felício LR, Grossi DB. Análise da força muscular dos estabilizadores do quadril e joelho em indivíduos com Síndrome da Dor Femoropatelar. Fisioter Pesq. 2014;21(4):327-32. 
4. Batista JS, Martins AD, Wibelinger LM. Avaliação da força muscular (torque muscular) de flexores e extensores de joelho de indivíduos jovens. EFDeportes.com. 2012;17(168):81-93.

5. Araújo CGS. Correlação entre métodos lineares e adimensionais de avaliação da mobilidade articular. Rev Bras Ciên e Mov. 2000;8(2):25-32.

6. Lima MA, Silva VF. Correlaçáo entre a resistência de força e flexibilidade dos músculos posteriores de coxa de desportistas amadores de futebol de campo. Fit Perf J. 2006;5(6):376-82.

7. Cortes AA, Montenegro A, Agra AC, Ernesto C, Andrade Júnior MS. A influência do treinamento de força na flexibilidade. Rev Vida e Saúde. 2002;1(2):19-26.

8. Achour Junior A. Exercícios de alongamento: anatomia e fisiologia. 4. ed. São Paulo: Manole; 2002.

9. Di Alencar TAM, Matias KFS. Princípios fisiológicos do aquecimento e alongamento muscular na atividade esportiva. Rev Bras Med Esporte. 2010;16(3):230-4.

10. Badaro AFV, Silva AH, Beche D. Flexibilidade versus alongamento: esclarecendo as diferenças. Rev Cent Ciênc Saúde. 2007;33(1):32-6.

11. Cyrino ES, Oliveira AR, Leite JC. Porto DB, Dias RMR, Segatin AQ, et al. Comportamento da flexibilidade após 10 semanas de treinamento com pesos. Rev Bras Med Esporte. 2004;10(4):23-33.

12. Rodrigues CEC, Dantas EHM. Efeito do treinamento de força sobre a flexibilidade. Fit Perf J. 2002;1(2):29-41.

13. Brasil. Ministério da Saúde. Vigitel Brasil 2013: vigilância de fatores de risco e proteção para doenças crônicas por inquérito telefônico. [Internet]. Brasília, DF: Ministério da Saúde; 2014. [citado em 2017 out. 31]. Disponível em: https://goo.gl/JmUiAi

14. Raimundo AKS, Moreira D, Santana LA. Manual fotográfico de goniometria e fleximetria: incluindo teste de retração muscular. 2 ed rev e atualizada. Brasília, DF: Thesaurus; 2010 .

15. Higajo N, Andrade DRE, Pereira MHN. Relação entre a flexibilidade e a força dos membros inferiores em voleibolistas de alto nível. Rev Bras Ciên e Mov. 1991;5(3):7-12.

16. Carvalho ACG, Paula KC, Azeredo TMC, Nóbrega ACL. Relação entre flexibilidade e força muscular em adultos jovens de ambos os sexos. Rev Bras Med Esporte. 1998;4(1):9-20.

17. Silva PH, Souza NTA, Muniz V, Dutra DSG. Influência do treinamento de força muscular na flexibilidade de alunos de uma academia de ginástica de Muriaé-MG. Revista Inspirar. 2009;1(3):34-45.

18. Nahas MV. Atividade física, saúde e qualidade de vida: conceitos e sugestóes para um estilo de vida ativo. Londrina: Midiograf; 2006.

19. McArdle WD, Katch FI, Katch VL. Fisiologia do exercício: energia, nutrição e desempenho humano. 6 ed. Rio de Janeiro: Guanabara Koogan; 2008.

20. Melegario SM, Simão R, Vale RGS, Batista LA, Novaes JS. A influência do ciclo menstrual na flexibilidade em praticantes de ginástica de academia. Rev Bras Med Esporte. 2006;12(3):18-31.

\section{Como citar este artigo:}

Matias AGC, Correia ALS, Tavares FM. Força, flexibilidade e espasticidade dos extensores do joelho em praticantes de musculação. Rev. Aten. Saúde. 2017;15(54):37-43. 